\title{
miR-205-5p/PTK7 axis is involved in the proliferation, migration and invasion of colorectal cancer cells
}

\author{
SHUO CHEN $^{1}$, YAN WANG ${ }^{2}$, YINAN SU ${ }^{1}$, LIN ZHANG $^{1}$, MINGQING ZHANG ${ }^{1}$, \\ XUEQING LI ${ }^{1}$, JUAN WANG ${ }^{1}$ and XIPENG ZHANG ${ }^{1}$ \\ ${ }^{1}$ Department of Colorectal Surgery, The People's Hospital of Tianjin, Tianjin 300121; \\ ${ }^{2}$ Department of Pathology, Affiliated Hospital of Shandong University of Traditional Chinese Medicine, \\ Jinan, Shandong 250014, P.R. China
}

Received June 20, 2016; Accepted April 24, 2017

DOI: $10.3892 / \mathrm{mmr} .2018 .8650$

\begin{abstract}
MicroRNAs (miRNAs) are small non-coding RNAs, which are critical in a diverse range of biological processes, including development, differentiation, homeostasis, and in the formation of diseases by accelerating and/or inhibiting the translation of mRNAs. The present study aimed to examine the potential role of miRNA (miR)-205-5p in the developmental process of colorectal cancer (CRC) through protein-tyrosine kinase 7 (PTK7). Initially, TargetScan was used to predict the miRNA target sites in the sequence of the PTK7 3'-untranslated region. It was then found that the mRNA expression level of miR-205-5p was lower in CRC cells, determined using reverse transcription-quantitative polymerase chain reaction analysis, and there was a negative correlation between miR-205-5p and PTK7 in CRC tissues. It was also found that miR-205-5p regulated the gene transcription of PTK7, determined using a luciferase reporter assay. The results of RT-qPCR and western blot analyses in human colorectal cancer revealed that miR-205-5p suppressed the expression of PTK7. Finally, it was revealed that miR-205-5p restricted the proliferation ability of CRC cells through inhibiting PTK7, which was determined using colony forming and 3-(4,5-dimethylthiazol-2-yl)-2,5-diphenyltetrazolium bromide assays. miR-205-5p accelerated cell apoptosis through inhibiting PTK7, demonstrated using Annexin V-FITC/propidium iodide staining. The results of a Transwell assay indicated that miR-205-5p inhibited the migration and invasion abilities of CRC cells through inhibiting PTK7. Therefore, miR-205-5p is involved in the proliferation, migration and invasion of CRC through inhibiting PTK7.
\end{abstract}

Correspondence to: Dr Xipeng Zhang, Department of Colorectal Surgery, The People's Hospital of Tianjin, 190 Jieyuan Road, Tianjin 300121, P.R. China

E-mail: zhangxipeng20165@sina.com

Key words: microRNA-205-5p, protein-tyrosine kinase 7, colorectal cancer, migration, invasion

\section{Introduction}

Colorectal cancer (CRC) is a frequently occurring type of cancer and is a primary contributor to morbidity and mortality rates worldwide (1). The incidence rates of CRC have gradually increased in developing countries, which previously showed a decrease in cases of CRC (2). Although methods have become available for the diagnosis and treatment of CRC during the last few decades, the overall five-year survival rate remains at $40-45 \%$ due to the limited ability to detect cancer at an early stage and provide prognostic predictions (3). At present, the molecular and functional mechanisms of CRC remain to be fully elucidated. Therefore, investigations aimed at determining biomarkers and effective molecular targets for CRC are urgently required.

MicroRNAs (miRNAs), which are non-coding RNAs of $\sim 20$ nucleotides, are involved in post-transcriptional regulation by targeting the 3 'untranslated region (UTR) of target genes (4-6). There have been an increasing number of studies showing that miRNAs are vital in the occurrence and development of various diseases, including cancer in humans $(4,7-9)$. Increasing evidence indicates that miRNAs are involved in the regulation of various biological processes, including proliferation, differentiation, apoptosis, migration and invasion (10). Several studies have indicated that certain miRNAs are involved in the developmental process of CRC, including miR-135b (11), miR-34a (12), miR-25 (13) and miR-21 (14). However, the biological functions and molecular mechanisms of miR-205-5p in CRC remain to be fully elucidated.

Protein-tyrosine kinase 7 (PTK7) belongs to the defective receptor protein-tyrosine kinases, and includes an extracellular domain, a transmembrane domain and a tyrosine kinase domain $(15,16)$. PTK7 is involved in the development of planar cell polarity, functioning as a regulator. Studies have indicated that PTK7 is involved in the Wnt pathway and PCP signaling pathway (17-19). Studies have also demonstrated that PTK7 is expressed at high levels in various types of cancer, including colon cancer (20), lung cancer (21), gastric cancer (22) and acute myeloid leukemia (23). Studies have also shown that PTK7 can affect the proliferation and invasion abilities of liposarcoma cells (24), and the migration and invasion abilities mediated by vascular endothelial growth factor (25). 
However, the interaction and association between miR-205-5p and PTK7, and the effects of miR-205-5p on the proliferation, migration and invasion abilities of CRC through PTK7 remain to be elucidated.

The present study investigated the potential role of miR-205-5p in the development of CRC through PTK7. The miRNA target sites in the sequence of the PTK7 3'UTR were predicted, which revealed that the expression of miR-205-5p was low in CRC. The correlation between miR-205-5p and PTK7 was examined in CRC tissues and the regulatory association between miR-205-5p and PTK7 was examined in CRC cells. The study also aimed to measure the effects of miR-205-5p on the proliferation, apoptosis, migration and invasion abilities of CRC cells through PTK7.

\section{Materials and methods}

Cell lines and transfection. HT29 and SW480 human CRC cell lines were purchased from the American Type Culture Collection (Manassas, VA, USA). The HT29 and SW480 cells were cultured at $37^{\circ} \mathrm{C}$ in an appropriate incubator containing 5\% $\mathrm{CO}_{2}$ in RPMI 1640 medium (Invitrogen; Thermo Fisher Scientific, Inc., Waltham, MA, USA) containing $10 \%$ fetal bovine serum (Gibco; Thermo Fisher Scientific, Inc.), penicillin $(100 \mathrm{U} / \mathrm{ml})$ and streptomycin $(100 \mu \mathrm{g} / \mathrm{ml})$. For treatment, $2 \times 10^{5}$ HT29 and SW480 cells were seeded into 6-well plates and then transfected with $200 \mu \mathrm{l}$ mature hsa-miR-NC (negative control) and the predicted miRNAs [predicted using TargetScan (http://www.targetscan.org/); miRBase (http://www .mirbase.org/), and MISIM (http://cmbi.bjmu.edu.cn/misim)], including hsa-miR-409-5p, hsa-miR-205-5p, hsa-miR-495-3p, hsa-miR-5688, and hsa-miR-503-5p (GenePharma Co., Ltd., Shanghai, China), respectively, for $72 \mathrm{~h}$. The miR-205-5p mimic sequence was 5'-UCCUUCAUUCCACCGGAGUCUG-3', the miR-control sequence was 5'-ACUACUGAGUGACAGUAG A-3', the inhibitor NC sequence was 5'-CAGUACUUUUGU GUAGUACAA-3', and the miR-205-5p inhibitor sequence was 5'-CAGACUCCGGUGGAAUGAAGGA-3'. The HT29 and SW480 cells were then transfected with miR-205-5p (50 nM), miR-control (50 nM), inhibitor NC (50 nM), and miR-205-5p inhibitor (50 nM), respectively. Finally, HT29 and SW480 cells were transfected with miR-control, miR-205-5p, miR-205-5p and vector, and miR-205-5p and PTK7, respectively, for $72 \mathrm{~h}$. All transfections were performed with Lipofectamine ${ }^{\mathrm{TM}} 3000$ (Invitrogen; Thermo Fisher Scientific, Inc.) according to the manufacturer's protocol.

Clinical specimens. In the present study, tissue samples were collected from 46 patients (age 50.34 +5.87 years, range 29-91; man/woman=25/21) with CRC in The People's Hospital of Tianjin (Tianjin, China) between January 2015 and November 2016. All tissue samples were verified by a trained pathologist and were immediately preserved at $-80^{\circ} \mathrm{C}$ until further use. The tumor grades were defined according to the criteria of World Health Organization (26). Written informed consent was provided by all patients. The present study was approved by the institutional ethics committee at the People's Hospital of Tianjin.

Reverse transcription-quantitative polymerase chain reaction (RT-qPCR) analysis. As described previously (27), total RNA was extracted from the CRC tissues, the matched adjacent noncancerous tissues, and the treated HT29 and SW480 cells using TRIzol reagent (Invitrogen; Thermo Fisher Scientific, Inc.) according to the manufacturer's protocol. Tissues $(100 \mathrm{mg})$ were treated with liquid nitrogen, and then ground into powder; the cell suspensions were centrifuged $(1,000 \mathrm{x} \mathrm{g}$, $\left.5 \mathrm{~min}, 4^{\circ} \mathrm{C}\right)$. Trizol $(1 \mathrm{ml})$ was added and ground for $5 \mathrm{~min}$ on ice, and then $0.2 \mathrm{ml}$ chloroform was added and centrifuged $\left(12,000 \times \mathrm{g}, 15 \mathrm{~min}, 4^{\circ} \mathrm{C}\right)$. The supernatant solution was obtained, precipitated by alcohol, and then centrifuged $\left(7,500 \times \mathrm{g}, 5 \mathrm{~min}, 4^{\circ} \mathrm{C}\right)$. RNA purity can be detected using the NanoDrop (Thermo Fisher Scientific, Inc., Wilmington, DE, USA). The optical density ${ }_{260 / 280}$ ratio is used as indicator for RNA purity. A ratio $>1.8$ is regarded as suitable for gene expression measurements. Total RNA $(1 \mu \mathrm{g})$ was reverse transcribed using the RevertAid First Strand cDNA Synthesis kit (Fermentas; Thermo Fisher Scientific, Inc.). The thermocycling conditions were $25^{\circ} \mathrm{C}, 5 \mathrm{~min} ; 42^{\circ} \mathrm{C}, 60 \mathrm{~min} ; 70^{\circ} \mathrm{C}$, 10 min. A SYBR-Green PCR Master Mix kit (Takara Bio, Inc., Otsu, Japan) was used to detect the mRNA expression levels of PTK7 and miR-205-5p. The reaction volumes for RT-qPCR were 5.0 $\mu \mathrm{l} \mathrm{SYBR}{ }^{\circledR}$ Premix Ex Taq ${ }^{\mathrm{TM}}$ II $(2 \mathrm{X}), 0.4 \mu \mathrm{l}$ PCR Forward Primer $(10 \mu \mathrm{M}), 0.4 \mu \mathrm{l}$ PCR Reverse Primer (10 $\mu \mathrm{M}), 0.2 \mu 1 \mathrm{ROX}$ Reference Dye (50X), $1.0 \mu \mathrm{l}$ cDNA template and $3.0 \mu \mathrm{lddH} 2 \mathrm{O}$. Reaction steps: $95^{\circ} \mathrm{C}$ for $30 \mathrm{sec}$ as the first step in a loop; $95^{\circ} \mathrm{C}$ for $5 \mathrm{sec}, 60^{\circ} \mathrm{C}$ for $34 \mathrm{sec}$ as the second step, a total of 40 cycles. The primer sequences were as follows: GAPDH, forward 5'-CCTCGTCTCATAGAC AAGATGGT-3' and reverse 5'-GGGTAGAGTCATACTGGA ACATG-3' (internal control); PTK7, forward 5'-CAGTTC CTGAGGATTTCCAAGAG-3' and reverse 5'-TGCATAGGG CCACCTTC-3'; hsa-miR-205-5p, 5'-TCCTTCATTCCACCG GAGTCTG-3'; U6, forward 5'-CTCGCTTCGGCAGCACA-3' and reverse 5'-AACGCTTCACGAATTTGCGT-3'. All the primers above were synthesized by IDT (Coralville, IA, USA). The fold change in expression was determined using the $2^{-\Delta \Delta \mathrm{Cq}}$ method (28).

Western blot analysis and antibodies. The treated HT29 and SW480 cells were lysed in lysis buffer containing a protease inhibitor cocktail (Sigma-Aldrich; Merck KGaA, Darmstadt, Germany). The concentrations of proteins were measured using a bicinchoninic acid Protein Assay kit (Thermo Fisher Scientific, Inc.). Equivalent quantities of protein were separated by $10 \%$ SDS-PAGE on gels and then transferred onto polyvinylidene difluoride (PVDF) membranes (EMD Millipore, Billerica, MA, USA). The PVDF membranes were blocked in 5\% skim milk (BD Biosciences, Franklin Lakes, $\mathrm{NJ}$, USA) for $2 \mathrm{~h}$ at room temperature. The PVDF membranes were then incubated with anti-PTK7 antibody (1:1,000; cat. no. MAB4499; R\&D Systems, Inc., Minneapolis, MN, USA); anti-GAPDH antibody (1:4,000; cat. no. 12255; Cell Signaling Technology, Inc., Beverly, MA, USA) at $4^{\circ} \mathrm{C}$ overnight, and were then incubated with HRP-conjugated secondary antibodies (goat anti-mouse; 1:5,000; cat. no. SC-2005, Santa Cruz Biotechnology, Inc., Dallas, TX, USA; goat anti-rabbit; 1:5,000; cat. no. SC-2004, Santa Cruz Biotechnology, Inc.) for $1 \mathrm{~h}$ at room temperature. Finally, the proteins were detected using an enhanced chemiluminescence detection kit (EMD Millipore, Billerica, MA, USA). The signals were detected 
using a chemiluminescence detection system with Super Signal West Pico Chemiluminescent Substrate (Thermo Fisher Scientific, Inc., cat. no. 34080). Anti-GAPDH antibody was used as an internal control.

Luciferase reporter assays. The sequences of the wild-type (WT) and mutant type (Mut) PTK7-3'UTR were amplified by PCR using human genomic DNA of the HT29 cell line and cloned into the pGL3-promoter vector (Promega Corporation, Madison, WI, USA; cat. no. E1751). The HT29 and SW480 cells $\left(5 \times 10^{4}\right.$ cells/well) were cultured in 24 -well plates and co-transfected with $50 \mathrm{nM}$ miR-205-5p, miR-control, inhibitor $\mathrm{NC}$, or $100 \mathrm{nM}$ miR-205-5p inhibitor, respectively with $15 \mathrm{ng}$ of WT pGL3-promoter-PTK7-3'UTR or $15 \mathrm{ng}$ Mut type pGL3-promoter-PTK7-3'UTR, and the Renilla plasmid (RL-SV40) using Lipofectamine 3000 (Invitrogen; Thermo Fisher Scientific, Inc.) according to the manufacturer's protocol. According to the manufacturer's protocol, the luciferase activity of PTK7 was detected using a Dual-Luciferase reporter assay system (Promega Corporation). The duration was $10 \mathrm{~h}$ between activity measurement and transfection and the results were normalized to pRL-CMV Renilla.

Colony formation assay. The HT29 and SW480 cells were transfected with miR-control, miR-205-5p, miR-205-5p and vector, and miR-205-5p and PTK7, respectively, for $72 \mathrm{~h}$. The treated HT29 and SW480 cells were incubated in complete medium for 14 days. The colonies were fixed with methanol for $15 \mathrm{~min}$ at room temperature, and dyed with giemsa dye solution for $10 \mathrm{~min}$ at room temperature. The colonies were then identified and counted under a light microscope (BX51; Olympus Corporation, Tokyo, Japan).

3-(4,5-dimethylthiazol-2-yl)-2,5-diphenyltetrazolium bromide (MTT) assay. The treated HT29 and SW480 cells $(2,000$ cells/well) were seeded in 96 -well plates with complete medium for 0, 24 and 48 h, respectively. Each group consisted of five wells and each well was treated with MTT (20 $\mu \mathrm{l} /$ well) solution (5 mg/ml; Sigma-Aldrich; Merck KGaA) at $0,12,24$ and $48 \mathrm{~h}$. After $4 \mathrm{~h}, 100 \mu \mathrm{l}$ dimethyl sulfoxide (Sigma-Aldrich, Merck KGaA) was added to dissolve the crystal. The absorbance (optical density) was detected using a microplate reader (BioTek Instruments, Inc., Winooski, VT, USA) at $570 \mathrm{~nm}$.

Flow cytometric analysis of cell apoptosis. According to the manufacturer's protocol, the treated HT29 and SW480 cells were stained with Annexin V-fluorescein isothio-cyanate (FITC)/propidium iodide (PI) kit (cat. no. 4830-01-K; R\&D systems, Inc.). Samples were analyzed for apoptosis using a FACSCalibur flow cytometer (BD Biosciences). FlowJo software 7.6.5 (Tree Star Inc., Ashland, OR, USA) was used to analyze the results of the flow cytometry.

Migration and invasion assays. For the migration assay, the treated HT29 and SW480 cells (1×105 cells/well) were seeded in the top of each well containing serum-free medium, and $600 \mu \mathrm{l}$ complete medium was added to the lower chamber. After $24 \mathrm{~h}$, the migrated cells were fixed with $4 \%$ paraformaldehyde for $30 \mathrm{~min}$ at room temperature and stained with
$0.1 \%$ crystal violet solution (Sigma-Aldrich; Merck KGaA) for 20 mins at room temperature. The migrated cells were identified and counted using a light microscope (BX51; Olympus Corporation). For the invasion assay, the diluted Matrigel (BD Biosciences,) was added to the Transwell chamber for $1 \mathrm{~h}$ at $37^{\circ} \mathrm{C}$, and the remaining steps were similar to those of the migration assay.

Statistical analysis. The data were analyzed using SPSS 18.0 version (SPSS, Inc. Chicago, IL, USA). The results were compared using one-way analysis of variance followed by Dunnett's posttest for multiple comparisons. All results are expressed as the mean \pm standard deviation from three replicates. $\mathrm{P}<0.05$ was considered to indicate a statistically significant difference.

\section{Results}

Identification of PTK7-integrated miRNAs. To identify miRNAs, which were potential target sites in the sequence of the PTK7 3'UTR. TargetScan (http://www.targetscan.org/) was used. It was found that there were five potential miRNAs, including hsa-miR-409-5p, hsa-miR-205-5p, hsa-miR-495-3p, hsa-miR-5688 and hsa-miR-503-5p (Fig. 1A). The HT29 and SW480 cells were then transfected with hsa-miR-NC (negative control) and the predicted miRNAs (miR-409-5p, miR-205-5p, miR-495-3p, miR-5688, and miR-503-5p, respectively). The results revealed that the mRNA expression level of PTK7 was decreased in HT29 cells transfected with miR-205-5p, compared with that in the NC cells $(\mathrm{P}<0.05$; Fig. 1B). Similarly, the mRNA expression level of PTK7 was decreased in SW480 cells transfected with miR-205-5p, compared with that in the $\mathrm{NC}$ cells $(\mathrm{P}<0.05$; Fig. 1C). To investigate whether miR-205-5p was physically associated with PTK7 in CRC tissues $(n=46)$, the correlation between the expression of miR-205-5p and PTK7 in CRC tissues was detected using RT-qPCR analysis. The result showed that there was a negative correlation between the gene expression of PTK7 and miR-205-5p and in the CRC tissues (Fig. 1D).

miR-205-5p regulates the gene transcription of PTK7 and suppresses the expression of PTK7 in human CRC. The present study further demonstrated that miR-205-5p may directly regulate the transcriptional level of PTK7. According to the binding site of the miR-205-5p targeting PTK7-3'UTR, the promoter region of PTK7-3'UTR was designed and cloned into pMIR-report, including a WT (PTK7-3'UTR-WT) vector and Mut type (PTK7-3'UTR-Mut) vector (Fig. 2A). The PTK7-3'UTR-WT or PTK7-3'UTR-Mut luciferase reporter was co-transfected into HT29 and SW480 cells with the miR-control, miR-205-5p, inhibitor NC, and miR-205-5p inhibitor, respectively. The results of luciferase reporter gene assays indicated that miR-205-5p decreased the promoter activity of PTK7 in HT29 cells ( $\mathrm{P}<0.05$; Fig. 2B); and miR-205-5p decreased the promoter activity of PTK7 in SW480 cells ( $\mathrm{P}<0.05$; Fig. 2C). The results of the RT-qPCR analysis also showed that miR-205-5p decreased the mRNA expression level of PTK7 in the HT29 and SW480 cells; the inhibition of miR-205-5p by the inhibitor increased the mRNA expression level of PTK7 in the HT29 and SW480 cells (Fig. 2D). The results of the western blot 


\section{A}

Human PTK7 ENST00000230419.4 3' UTR length: 839

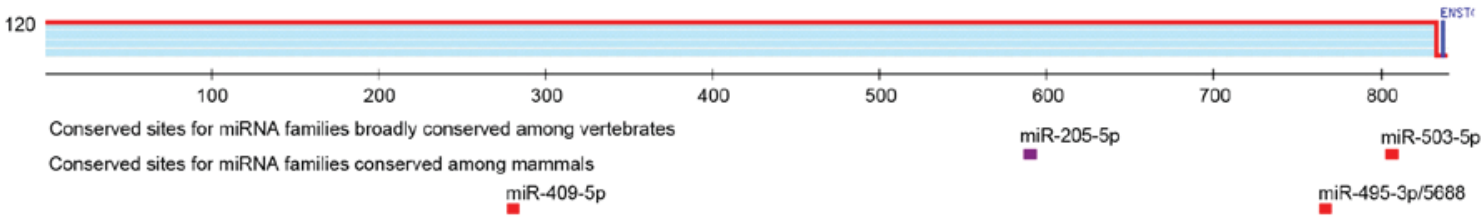

B

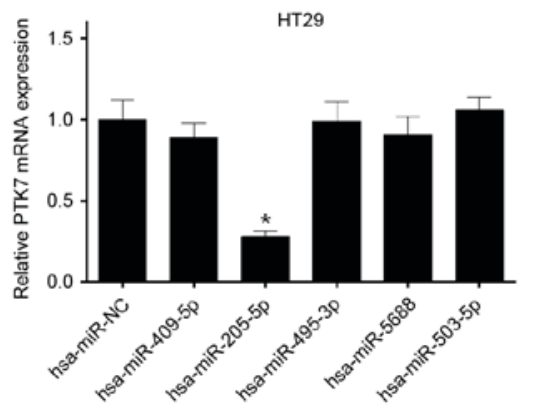

C

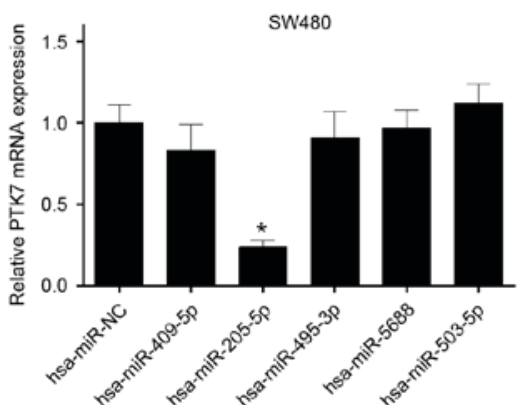

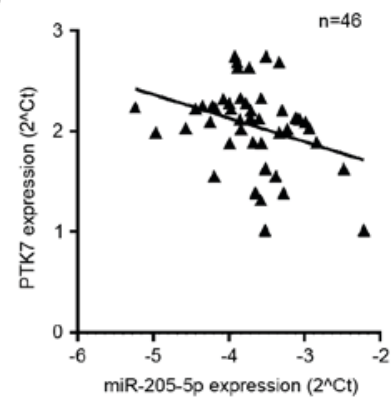

Figure 1. Identification of PTK7-integrated miRNAs. (A) miRNA target sites in the PTK7 3'UTR sequence were predicted using TargetScan. (B) RT-qPCR analysis was used to determine the mRNA expression level of PTK7 in HT29 cells transfected with hsa-miR-NC and the predicted miRNAs, including hsa-miR-409-5p, hsa-miR-205-5p, hsa-miR-495-3p, hsa-miR-5688 and hsa-miR-503-5p, respectively. (C) The mRNA expression level of PTK7 was detected using RT-qPCR analysis in SW480 cells treated as B. (D) Negative correlation between miR-205-5p and PTK7, analyzed using RT-qPCR analysis in colorectal cancer tissues $(\mathrm{n}=46)$. "P<0.05 vs. hsa-miR-NC group. miRNA/miR, microRNA; PTK7, protein-tyrosine kinase 7; NC, negative control; RT-qPCR, reverse transcription-quantitative polymerase chain reaction; UTR, untranslated region.
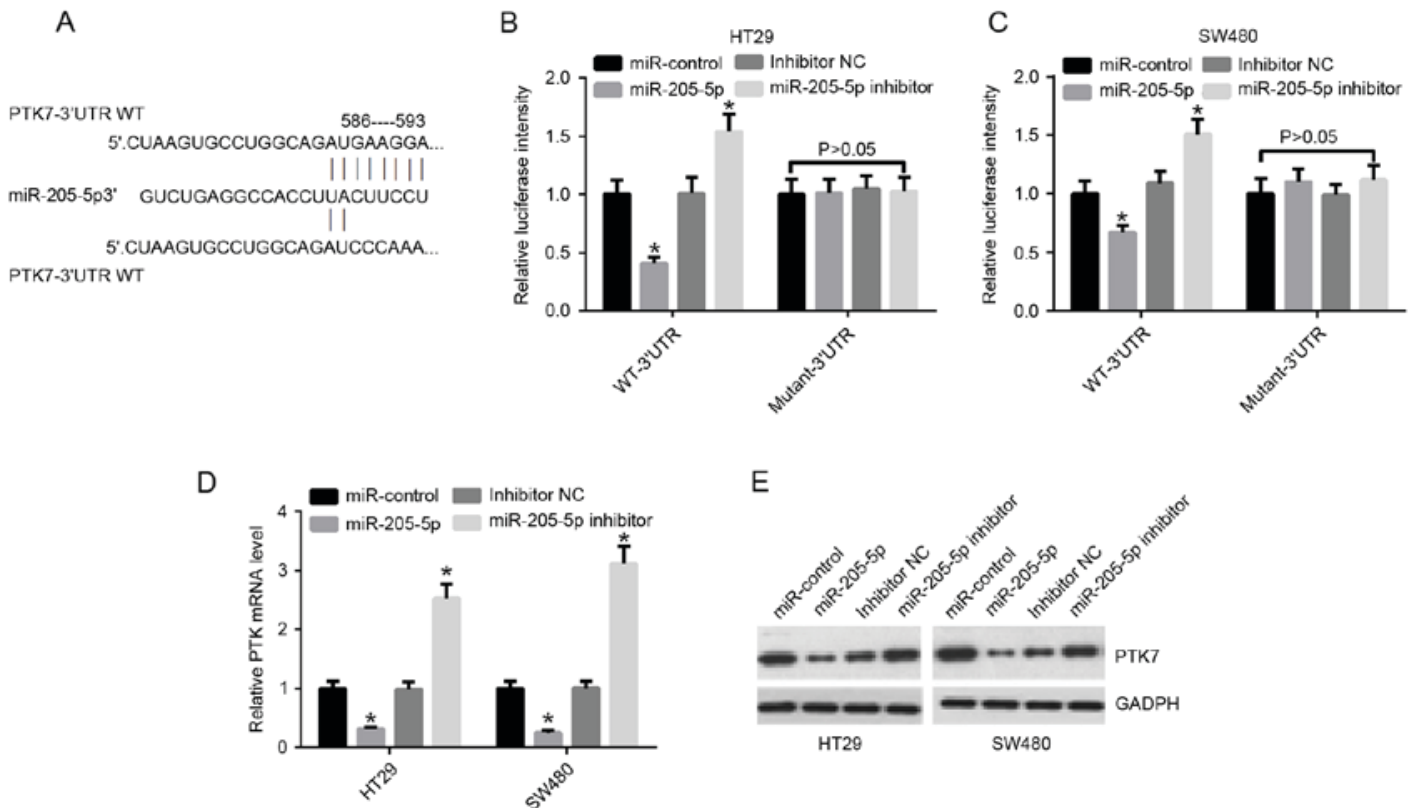

Figure 2. miR-205-5p regulates the gene transcription of PTK7 and suppresses the expression of PTK7 in human colorectal cancer. (A) Binding sites of miR-205-5p (586-593) targeting PTK7-3'UTR-WT and its mutant sequences (PTK7-3'UTR-Mut) are shown. The sites without connections indicate the mutation position. (B) PTK7-3'UTR-WT or PTK7-3'UTR-Mut luciferase reporter was co-transfected into HT29 cells with miR-control, miR-205-5p, inhibitor NC, and miR-205-5p inhibitor, respectively, for $48 \mathrm{~h}$. Luciferase activity of the PTK7 3'UTR was detected using a luciferase reporter gene assay. (C) PTK7-3'UTR-WT or PTK7-3'UTR-Mut luciferase reporters was co-transfected into SW480 cells with miR-control, miR-205-5p, inhibitor NC, and miR-205-5p inhibitor, respectively, for $48 \mathrm{~h}$. Luciferase activity of the PTK7 3'UTR was detected using the luciferase reporter gene assay. (D) Reverse transcription-quantitative polymerase chain reaction analysis of the mRNA expression levels of PTK1 in HT29 and SW480 cells transfected with miR-control, miR-205-5p, inhibitor NC, and miR-205-5p inhibitor, respectively. (E) Protein expression levels of PTK7, measured using western blot analysis, in HT29 and SW480 cells treated as in D. ${ }^{*} \mathrm{P}<0.05$ vs. miR-control. miR, microRNA; PTK7, protein-tyrosine kinase 7; WT, wild-type; Mut, mutant; UTR, untranslated region; NC, negative control.

analysis indicated that miR-205-5p also decreased the protein expression levels of PTK7 in the HT29 and SW480 cells; the inhibition of miR-205-5p by the inhibitor increased the protein expression level of PTK7 in HT29 and SW480 cells (Fig. 2E). 
A
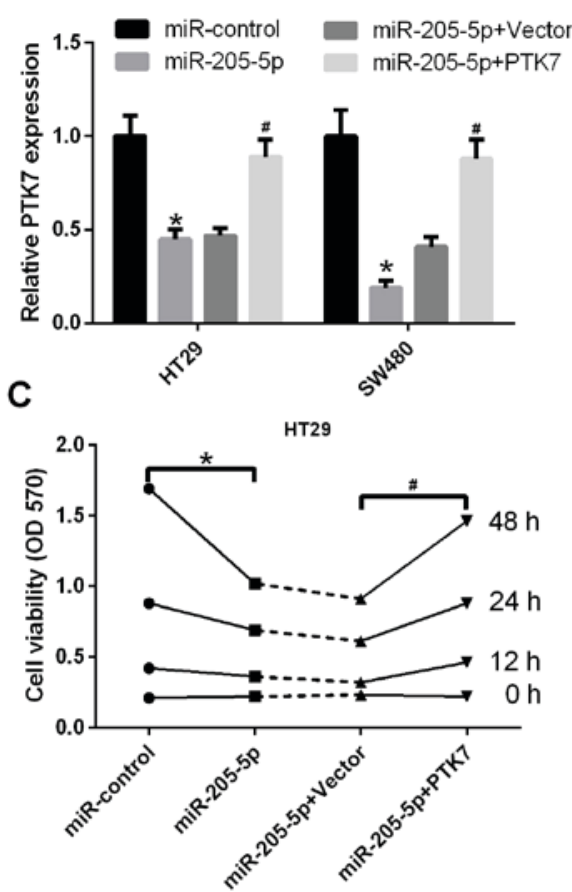

E

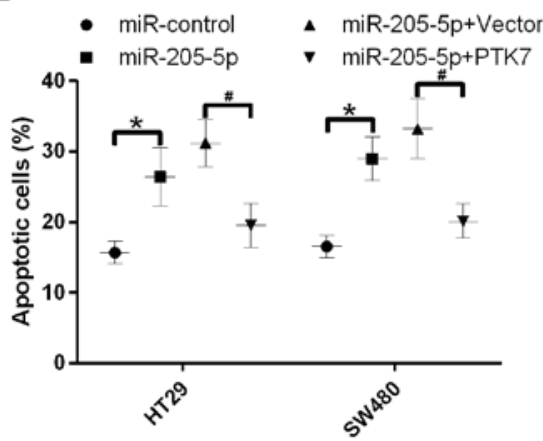

B

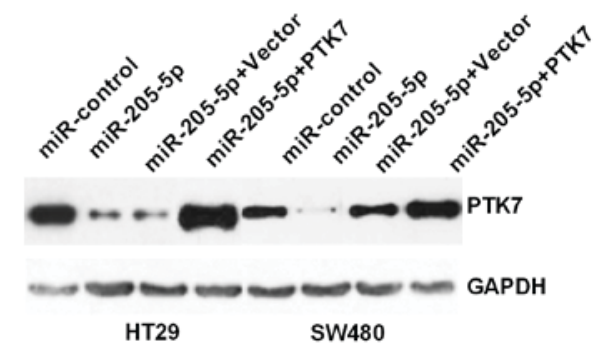

D

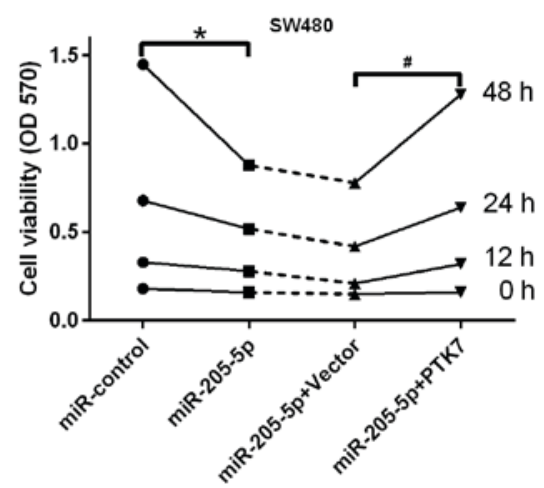

F

Colony formation assay

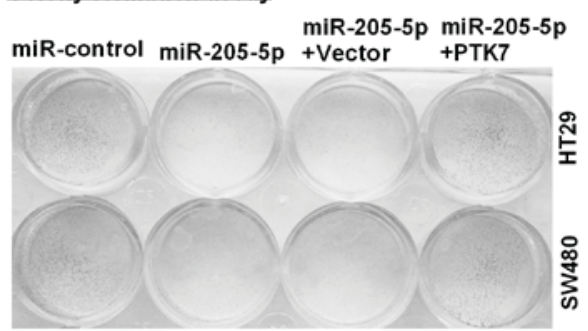

Figure 3. miR-205-5p accelerates cell proliferation, and inhibits apoptosis through PTK7 in CRC cells. (A) miR-205-5p inhibited the mRNA expression levels of PTK7 in HT29 and SW480 cells. The mRNA expression levels of PTK7 were detected using reverse transcription-quantitative polymerase chain reaction analysis in HT29 and SW480 cells transfected with miR-control, miR-205-5p, miR-205-5p and vector, miR-205-5p and PTK7, respectively ( $\mathrm{P}<0.05$ miR-205-5p, vs. NC; ${ }^{\text {"P }}<0.05$ miR-205-2p+PTK7 vs. miR-205-5p+vector). (B) Western blot analysis was used to measure the protein expression levels of PTK7 in HT29 and SW480 cells treated as in A. (C) An MTT assay was performed to determine the proliferation ability of HT29 cells transfected with miR-control, miR-205-5p, miR-205-5p and vector, and miR-205-5p and PTK7, respectively, at $0,12,24$ and $48 \mathrm{~h}{ }^{*} \mathrm{P}<0.05 \mathrm{miR}-205-5 \mathrm{p}, \mathrm{vs} . \mathrm{NC}$; ${ }^{\#} \mathrm{P}<0.05$ miR-205-2p+PTK7 vs. miR-205-5p+vector. (D) MTT assay was performed to detect proliferation ability of SW480 cells treated as in C. * $<0.05$ miR-205-5p, vs. NC; "P<0.05 miR-205-2p+PTK7 vs. miR-205-5p+vector). (E) HT29 and SW480 cells were transfected with miR-control, miR-205-5p, miR-205-5p and vector, and miR-205-5p and PTK7, respectively, and cell apoptosis was detected using Annexin V-FITC/PI staining. ${ }^{*} \mathrm{P}<0.05$ miR-205-5p, vs. NC; ${ }^{\#} \mathrm{P}<0.05$ miR-205-2p+PTK7 vs. miR-205-5p+vector. (F) Cell proliferation was detected using colony formation assays in HT29 and SW480 cells transfected with miR-control, miR-205-5p, miR-205-5p and vector, and miR-205-5p and PTK7, respectively. miR, microRNA; PTK7, protein-tyrosine kinase 7; MTT, 3-(4,5-dimethylthiazol-2-yl)-2,5-diphenyltetrazolium bromide; PI, propidium iodide.

miR-205-5p accelerates cell proliferation and inhibits apoptosis through PTK7 in CRC cells. The effects of miR-205-5p on the proliferation and apoptosis capacities of the CRC cells were investigated. The HT29 and SW480 cells were transfected with miR-control, miR-205-5p, miR-205-5p and vector, and miR-205-5p and PTK7, respectively. The mRNA expression level of PTK7 was detected using RT-qPCR analysis. The results demonstrated that miR-205-5p decreased the mRNA expression level of PTK7 in the HT29 and SW480 cells; PTK7-transfection increased the mRNA expression level of PTK7 mediated by miR-205-5p ( $<<0.05$; Fig. 3A). Simultaneously, the results of the western blot analysis showed that miR-205-5p inhibited the protein expression level of
PTK7 in the HT29 and SW480 cells; PTK7-transfection increased the protein expression level of PTK7 mediated by miR-205-5p (Fig. 3B). Subsequently, the MTT assays indicated that miR-205-5p inhibited the proliferation ability of HT29 cells; the overexpression of PTK7 promoted the proliferation ability of HT29 cells mediated by miR-205-5p $(\mathrm{P}<0.05$; Fig. 3C). It was also indicated that miR-205-5p inhibited the proliferation ability of SW480 cells; the overexpression of PTK7 promoted the proliferation ability of SW480 cells mediated by miR-205-5p ( $\mathrm{P}<0.05$; Fig. 3D). The apoptosis of cells was detected using Annexin V-FITC/PI staining. It was found that apoptosis was increased in HT29 and SW480 cells transfected with miR-205-5p, compared with those transfected with 
A

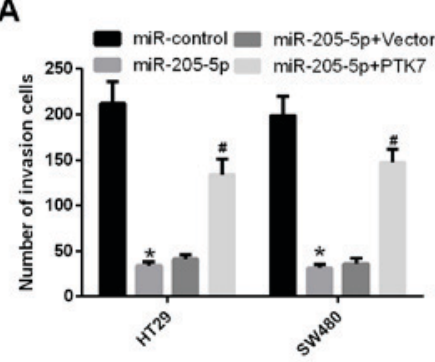

C

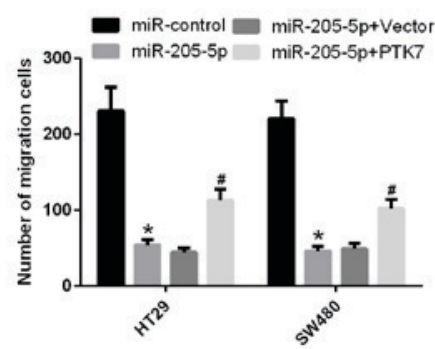

B

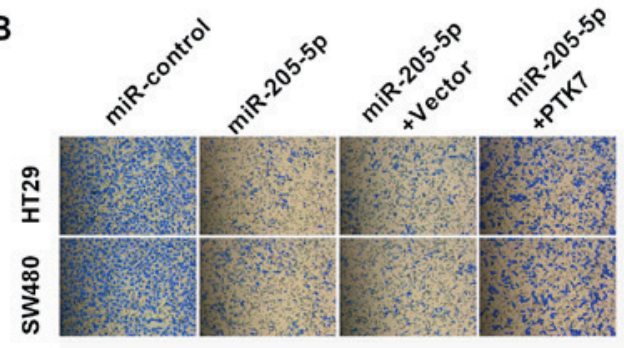

D

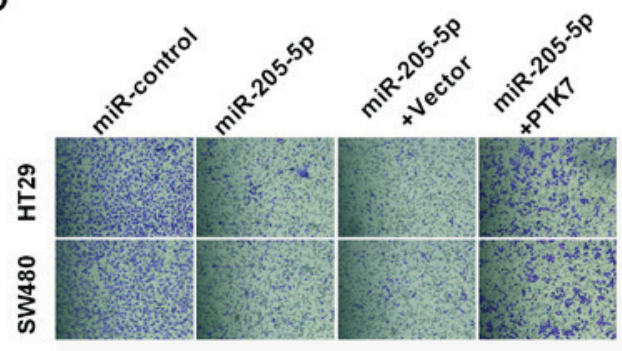

E

miR-205-5p/PTK7 axis in colorecal cancer

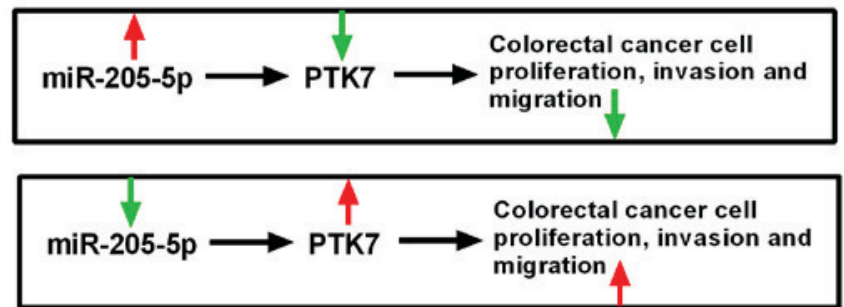

Figure 4. miR-205-5p promotes migration and invasion abilities of CRC cells through PTK7. (A) Invasion assays were performed in HT29 and SW480 cells transfected with miR-control, miR-205-5p, miR-205-5p and vector, and miR-205-5p and PTK7, respectively. Quantification of invasive cells was calculated. ${ }^{*} \mathrm{P}<0.05$ miR-205-5p, vs. NC; "P<0.05 miR-205-2p+PTK7 vs. miR-205-5p+vector. (B) Images of invasive cells (magnification, $\mathrm{x} 200$ ). (C) Migration assays were performed in HT29 and SW480 cells transfected with miR-control, miR-205-5p, miR-205-5p and vector, and miR-205-5p and PTK7, respectively. Quantification of invasive cells was calculated. *P<0.05 miR-205-5p, vs. NC; ${ }^{*} \mathrm{P}<0.05$ miR-205-2p+PTK7 vs. miR-205-5p+vector. (D) Images of migrated cells (magnification, x200). (E) Functional mechanism of PTK7-integrated miR-205-5p in CRC. The red arrows represent an increase and the green arrows represent a decrease. miR, microRNA; PTK7, protein-tyrosine kinase 7; CRC, colorectal cancer.

miR-control; the apoptosis was deceased in HT29 and SW480 cells transfected with miR-205-5p and PTK7, compared with those transfected with miR-205-5p and vector $(\mathrm{P}<0.05$; Fig. 3E). A colony formation assay was also performed to detect the proliferation ability. The results also indicated that miR-205-5p inhibited proliferation ability, and PTK7 promoted the proliferation ability mediated by miR-205-5p in the SW480 and HT29 cells (Fig. 3F).

miR-205-5p promotes the migration and invasion abilities of CRC cells through PTK7. The effects of the expression of miR-205-5p on the migration and invasion abilities of CRC cells were detected in HT29 and SW480 cells transfected with miR-control, miR-205-5p, miR-205-5p and vector, and miR-205-5p and PTK7, respectively. The results showed that the invasion capacities of the HT29 and SW480 cells transfected with miR-205-5p were significantly decreased compared with those transfected with miR-control $(\mathrm{P}<0.05)$; the invasion capacities of the HT29 and SW480 cells transfected with miR-205-5p and PTK7 were significantly increased, compared with the cells transfected with miR-205-5p and vector $(\mathrm{P}<0.05$; Fig. $4 \mathrm{~A}$ and
B). Similarly, the results showed that the migration capacities of the HT29 and SW480 cells transfected with miR-205-5p were significantly decreased, compared with those transfected with miR-control $(\mathrm{P}<0.05)$; the cell migration capacities of the HT29 and SW480 cells transfected with miR-205-5p and PTK7 were significantly increased, compared with those transfected with miR-205-5p and vector ( $\mathrm{P}<0.05$; Fig. $4 \mathrm{C}$ and $\mathrm{D})$.

$m i R-205-5 p / P T K 7$ axis in $C R C$. The results of the present study confirmed the functional mechanism of PTK7-integrated miR-205-5p in CRC. The overexpression of miR-205-5p inhibited the proliferation, migration and invasion abilities of CRC through inhibition of the expression of PTK7. The decreased expression of miR-205-5p accelerated the proliferation, migration and invasion abilities of CRC through activation of the expression of PTK7 (Fig. 4E).

\section{Discussion}

Several studies have demonstrated that PTK7 is expressed at high levels in various types of cancer, including CRC, 
liposarcoma, esophageal cancer, and gastric cancer (24,29-31). High expression levels of PTK7 have been associated with poor prognosis in esophageal cancer. PTK7 is involved in the proliferation, survival, invasion and migration of tumors, including CRC (32), esophageal cancer (30), and lung cancer (33). Furthermore, is have been shown that PTK7 may be a potential oncogene $(30,31,34)$. However, the regulatory association between PTK7 and miRNA remains to be fully elucidated.

miRNAs, a class of small non-coding RNAs of 19-24 nucleotides, are differentially expressed in various types of cancer suggesting the important function of miRNAs in tumorigenesis (35-37). An increasing number of studies have indicated that miRNAs can act as oncogenes or tumor suppressors $(36,37)$, and can affect the proliferation, metastasis, angiogenesis and inflammation of tumors by targeting mRNAs $(38,39)$. There is evidence that various miRNAs are associated with the occurrence and development of CRC. For example, miR-21 has been found to stimulate invasion, intravasation and metastasis in CRC by downregulating Pdcd4 (40); miR-135b, as a downstream effector of oncogenic pathways, also promotes the progression of CRC (11) and, as a potential tumor suppressor, miR-25 has been found to be involved in CRC by targeting small mothers against decapentaplegic 7 (13).

miR-218 inhibits cell cycle and promotes apoptosis of CRC cells (41); miR-498 is downregulated in CRC and affects the functions of CRC cells (42). Furthermore, the expression of miRNAs can provide biomolecular and prognostic characteristics $(43,44)$. However, the function of miR-205-5p in CRC remains to be fully elucidated.

In the present study, five potential miRNAs, including hsa-miR-409-5p, hsa-miR-205-5p, hsa-miR-495-3p, hsa-miR-5688 and hsa-miR-503-5p, were identified as potential target sites in the sequence of PTK7 3'UTR. It was indicated that the mRNA expression levels of PTK7 were decreased in HT29 and SW480 cells transfected with miR-205-5p, compared with levels in NC cells. In addition, there was a negative correlation between the gene expression of PTK7 and miR-205-5p in CRC tissues. It was confirmed that miR-205-5p directly regulated the transcriptional level of PTK7, with miR-205-5p simultaneously decreasing the mRNA and protein expression levels of PTK7 in HT29 and SW480 cells. It was also revealed that miR-205-5p accelerated the proliferation, migration and invasion abilities of CRC cells, and inhibited apoptosis through PTK7.

In conclusion, the results of the present study confirmed the functional mechanism of PTK7-integrated miR-205-5p in CRC. It was found that there was a negative correlation between miR-205-5p and PTK7 in CRC tissues. Furthermore, miR-205-5p was indicated to be involved in the processes of proliferation, apoptosis, migration and invasion in CRC through the regulation of PTK7.

\section{Acknowledgements}

The present study was supported by the Science Foundation of Chinese and Western Integrative Medicine of Zhejiang Province, China (No. 2014LYZ0017).

\section{References}

1. Ferlay J, Soerjomataram I, Dikshit R, Eser S, Mathers C, Rebelo M, Parkin DM, Forman D and Bray F: Cancer incidence and mortality worldwide: Sources, methods and major patterns in GLOBOCAN 2012. Int J Cancer 136: E359-E386, 2015.

2. Haggar FA and Boushey RP: Colorectal cancer epidemiology: Incidence, mortality, survival, and risk factors. Clin Colon Rectal Surg 22: 191-197, 2009.

3. Khair G, Monson JR and Greenman J: Epithelial molecular markers in the peripheral blood of patients with colorectal cancer. Dis Colon Rectum 50: 1188-1203, 2007.

4. Farazi TA, Hoell JI, Morozov P and Tuschl T (eds): MicroRNAs in human cancer. In: MicroRNA Cancer Regulation. Springer, New York, NY, pp1-20, 2013.

5. Djuranovic S, Nahvi A and Green R: A parsimonious model for gene regulation by miRNAs. Science 331: 550-553, 2011.

6. Kasinski AL and Slack FJ: MicroRNAs en route to the clinic: Progress in validating and targeting microRNAs for cancer therapy. Nat Rev Cancer 11: 849-864, 2011.

7. Baer C, Claus R and Plass C: Genome-wide epigenetic regulation of miRNAs in cancer. Cancer Res 73: 473-477, 2013.

8. Zaman MS, Maher DM, Khan S, Jaggi M and Chauhan SC: Current status and implications of microRNAs in ovarian cancer diagnosis and therapy. J Ovarian Res 5: 44, 2012.

9. Di Leva G and Croce CM: The role of microRNAs in the tumorigenesis of ovarian cancer. Front Oncol 3: 153, 2013.

10. Ambros V: The functions of animal microRNAs. Nature 431: 350-355, 2004.

11. Valeri N, Braconi C, Gasparini P, Murgia C, Lampis A, Paulus-Hock V, Hart JR, Ueno L, Grivennikov SI, Lovat F, et al: MicroRNA-135b promotes cancer progression by acting as a downstream effector of oncogenic pathways in colon cancer. Cancer Cell 25: 469-483, 2014.

12. Bu P, Chen KY, Chen JH, Wang L, Walters J, Shin YJ, Goerger JP, Sun J, Witherspoon M, Rakhilin N, et al: A microRNA miR-34a-regulated bimodal switch targets Notch in colon cancer stem cells. Cell Stem Cell 12: 602-615, 2013.

13. Li Q, Zou C, Zou C, Han Z, Xiao H, Wei H, Wang W, Zhang L, Zhang X, Tang Q, et al: MicroRNA-25 functions as a potential tumor suppressor in colon cancer by targeting Smad7. Cancer Lett 335: 168-174, 2013.

14. Yu Y, Kanwar SS, Patel BB, Oh PS, Nautiyal J, Sarkar FH and Majumdar AP: MicroRNA-21 induces stemness by downregulating transforming growth factor beta receptor 2 (TGF $\beta R 2$ ) in colon cancer cells. Carcinogenesis 33: 68-76, 2012.

15. Park SK, Lee HS and Lee ST: Characterization of the human full-length PTK7 cDNA encoding a receptor protein tyrosine kinase-like molecule closely related to chick KLG. J Biochem 119: 235-239, 1996.

16. Lee ST, Strunk KM and Spritz RA: A survey of protein tyrosine kinase mRNAs expressed in normal human melanocytes. Oncogene 8: 3403-3410, 1993.

17. Shnitsar I and Borchers A: PTK7 recruits dsh to regulate neural crest migration. Development 135: 4015-4024, 2008.

18. Lu X, Borchers AG, Jolicoeur C, Rayburn H, Baker JC and Tessier-Lavigne M: PTK7/CCK-4 is a novel regulator of planar cell polarity in vertebrates. Nature 430: 93-98, 2004.

19. Puppo F, Thomé V, Lhoumeau AC, Cibois M, Gangar A, Lembo F, Belotti E, Marchetto S, Lécine P, Prébet T, et al: Protein tyrosine kinase 7 has a conserved role in Wnt/ $\beta$-catenin canonical signalling. EMBO Rep 12: 43-49, 2011.

20. Saha S, Bardelli A, Buckhaults P, Velculescu VE, Rago C, St Croix B, Romans KE, Choti MA, Lengauer C, Kinzler KW and Vogelstein B: A phosphatase associated with metastasis of colorectal cancer. Science 294: 1343-1346, 2001.

21. Endoh H, Tomida S, Yatabe Y, Konishi H, Osada H, Tajima K, Kuwano H, Takahashi T and Mitsudomi T: Prognostic model of pulmonary adenocarcinoma by expression profiling of eight genes as determined by quantitative real-time reverse transcriptase polymerase chain reaction. J Clin Oncol 22: 811-819, 2004.

22. Gorringe KL, Boussioutas A and Bowtell DD; Melbourne Gastric Cancer Group, Peter Mac Micro ArrayFacility: Novel regions of chromosomal amplification at $6 \mathrm{p} 21,5 \mathrm{p} 13$, and 12 q14 in gastric cancer identified by array comparative genomic hybridization. Genes Chromosomes Cancer 42: 247-259, 2005. 
23. Müller-Tidow C, Schwäble J, Steffen B, Tidow N, Brandt B Becker K, Schulze-Bahr E, Halfter H, Vogt U, Metzger R, et al: High-throughput analysis of genome-wide receptor tyrosine kinase expression in human cancers identifies potential novel drug targets. Clinical Cancer Res 10: 1241-1249, 2004.

24. Gobble RM, Qin LX, Brill ER, Angeles CV, Ugras S, O'Connor RB, Moraco NH, Decarolis PL, Antonescu C and Singer S: Expression profiling of liposarcoma yields a multigene predictor of patient outcome and identifies genes that contribute to liposarcomagenesis. Cancer Res 71: 2697-2705, 2011.

25. Shin WS, Maeng YS, Jung JW, Min JK, Kwon YG and Lee ST: Soluble PTK7 inhibits tube formation, migration, and invasion of endothelial cells and angiogenesis. Biochem Biophys Res Commun 371: 793-798, 2008.

26. Travis WD, Brambilla E, Nicholson AG, Yatabe Y, Austin JHM Beasley MB, Chirieac LR, Dacic S, Duhig E, Flieder DB, et al: The 2015 World health organization classification of lung tumors: Impact of Genetic, clinical and radiologic advances since the 2004 Classification. J Thorac Oncol 10: 1243-1260, 2015.

27. Jiang L, Lai YK, Zhang J, Wang H, Lin MC, He ML and Kung HF: Targeting S100P inhibits colon cancer growth and metastasis by Lentivirus-mediated RNA interference and proteomic analysis. Mol Med 17: 709-716, 2011

28. Livak KJ and Schmittgen TD: Analysis of relative gene expression data using real-time quantitative PCR and the 2(-Delta Delta C(T)) method. Methods 25: 402-408, 2001.

29. Mossie K, Jallal B, Alves F, Sures I, Plowman GD and Ullrich A Colon carcinoma kinase-4 defines a new subclass of the receptor tyrosine kinase family. Oncogene 11: 2179-2184, 1995.

30. Shin WS, Kwon J, Lee HW, Kang MC, Na HW, Lee ST and Park JH: Oncogenic role of protein tyrosine kinase 7 in esophageal squamous cell carcinoma. Cancer Sci 104: 1120-1126, 2013.

31. Lin Y, Zhang LH, Wang XH, Xing XF, Cheng XJ, Dong B, Hu Y, Du H, Li YA, Zhu YB, et al: PTK7 as a novel marker for favorable gastric cancer patient survival. J Surg Oncol 106: 880-886, 2012.

32. Na HW, Shin WS, Ludwig A and Lee ST: The cytosolic domain of PTK7, generated from sequential cleavage by ADAM17 and $\gamma$-secretase, enhances cell proliferation and migration in colon cancer cells. J Biol Chem 287: 25001-25009, 2012.

33. Kim JH, Kwon J, Lee HW, Kang MC, Yoon HJ, Lee ST and Park JH: Protein tyrosine kinase 7 plays a tumor suppressor role by inhibiting ERK and AKT phosphorylation in lung cancer. Oncol Reports 31: 2708-2712, 2014.
34. Meng L, Sefah K, O'Donoghue MB, Zhu G, Shangguan D, Noorali A, Chen Y, Zhou L and Tan W: Silencing of PTK7 in colon cancer cells: Caspase-10-dependent apoptosis via mitochondrial pathway. PLoS One 5: e14018, 2010.

35. Bartel DP: MicroRNAs: Genomics, biogenesis, mechanism, and function. Cell 116: 281-297, 2004.

36. Esquela-Kerscher A and Slack FJ: Oncomirs-microRNAs with a role in cancer. Nat Rev Cancer 6: 259-269, 2006.

37. Croce CM and Calin GA: miRNAs, cancer, and stem cell division. Cell 122: 6-7, 2005.

38. Wang J, Paris PL, Chen J, Ngo V, Yao H, Frazier ML, Killary AM, Liu CG, Liang H, Mathy C, et al: Next generation sequencing of pancreatic cyst fluid microRNAs from low grade-benign and high grade-invasive lesions. Cancer Lett 356: 404-409, 2015.

39. Stahlhut $\mathrm{C}$ and Slack FJ: MicroRNAs and the cancer phenotype: Profiling, signatures and clinical implications. Genome Med 5: 111, 2013.

40. Asangani IA, Rasheed SA, Nikolova DA, Leupold JH, Colburn NH, Post S and Allgayer H: MicroRNA-21 (miR-21) post-transcriptionally downregulates tumor suppressor Pdcd4 and stimulates invasion, intravasation and metastasis in colorectal cancer. Oncogene 27: 2128-2136, 2008.

41. He X, Dong Y, Wu CW, Zhao Z, Ng SS, Chan FK, Sung JJ and Yu J: MicroRNA-218 inhibits cell cycle progression and promotes apoptosis in colon cancer by downregulating BMI1 polycomb ring finger oncogene. Mol Med 18: 1491-1498, 2012.

42. Gopalan V, Smith RA and Lam AK: Downregulation of microRNA-498 in colorectal cancers and its cellular effects. Exp Cell Res 330: 423-428, 2015.

43. Calin GA, Ferracin M, Cimmino A, Di Leva G, Shimizu M, Wojcik SE, Iorio MV, Visone R, Sever NI, Fabbri M, et al: A MicroRNA signature associated with prognosis and progression in chronic lymphocytic leukemia. N Engl J Med 353: 1793-1801, 2005.

44. Roldo C, Missiaglia E, Hagan JP, Falconi M, Capelli P, Bersani S, Calin GA, Volinia S, Liu CG, Scarpa A and Croce CM: MicroRNA expression abnormalities in pancreatic endocrine and acinar tumors are associated with distinctive pathologic features and clinical behavior. J Clin Oncol 24: 4677-4684, 2006.

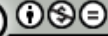

This work is licensed under a Creative Commons Attribution-NonCommercial-NoDerivatives 4.0 International (CC BY-NC-ND 4.0) License. 